\title{
Etiology and pathogenesis of epithelial ovarian cancer
}

\author{
Samuel C. Mok ${ }^{\mathrm{a}, \mathrm{b}, *}$, Joseph Kwong ${ }^{\mathrm{a}}$, William R. Welch ${ }^{\mathrm{c}}$, Goli Samimid,e, Laurent Ozbun ${ }^{\mathrm{d}}$, \\ Tomas Bonome $^{\mathrm{d}}$, Michael J. Birrer ${ }^{\mathrm{d}}$, Ross S. Berkowitz ${ }^{\mathrm{a}, \mathrm{b}}$ and Kwong-Kwok Wong ${ }^{\mathrm{f}}$ \\ ${ }^{a}$ Department of Obstetrics, Gynecology, and Reproductive Biology, Laboratory of Gynecologic Oncology, Brigham \\ and Women's Hospital, Harvard Medical School, Boston, MA 02115, USA \\ ${ }^{\mathrm{b}}$ Gillette Center For Women's Cancer, Dana-Farber/Harvard Cancer Center, Boston, MA 02115, USA \\ ${ }^{\mathrm{c}}$ Department of Pathology, Brigham and Women's Hospital, Harvard Medical School, Boston, MA 02115 USA \\ ${ }^{\mathrm{d}}$ Cell and Cancer Biology Branch, Center for Cancer Research, National Cancer Institute, Bethesda, MD 20892, \\ USA \\ ${ }^{\mathrm{e}}$ Cancer Prevention Fellowship Program, Office of Preventative Oncology, Division of Cancer Prevention, \\ Bethesda, MD 20892, USA \\ ${ }^{\mathrm{f}}$ Department of Gynecologic Oncology, The University of Texas M. D. Anderson Cancer Center, Houston, TX \\ 77030, USA
}

\begin{abstract}
Ovarian cancer is complex disease composed of different histological grades and types. However, the underlying molecular mechanisms involved in the development of different phenotypes remain largely unknown. Epidemiological studies identified multiple exogenous and endogenous risk factors for ovarian cancer development. Among them, an inflammatory stromal microenvironment seems to play a critical role in the initiation of the disease. The interaction between such a microenvironment, genetic polymorphisms, and different epithelial components such as endosalpingiosis, endometriosis, and ovarian inclusion cyst in the ovarian cortex may induce different genetic changes identified in the epithelial component of different histological types of ovarian tumors. Genetic studies on different histological grades and types provide insight into the pathogenetic pathways for the development of different disease phenotypes. However, the link between all these genetic changes and the etiological factors remains to be established.
\end{abstract}

Keywords: Ovarian cancer, microenvironment, inflammation, pathogenesis

\section{Introduction}

Ovarian cancer kills more American women than any other gynecologic cancer and is, for the same group, the fifth most common cause of cancer-related death [1]. Although all human ovary cells, including epithelial, stromal, and germ cells, may undergo neoplastic transformation, $80 \%$ to $90 \%$ of malignant ovarian tumors come from the single layer of epithelial cells covering

${ }^{*}$ Corresponding author: Samuel C. Mok, Laboratory of Gynecologic Oncology, Brigham and Women's Hospital, BLI-447, 221 Longwood Avenue, Boston, MA 02115, USA. Tel.: +1 617278 1096; Fax: +1 617 9750818; E-mail: scmok@ rics.bwh.harvard.edu. the ovaries [2]. The human ovarian surface epithelium (HOSE) is believed to originate from the mesothelium of the embryonic gonad (the mullerian epithelium). In contrast to colorectal cancer, ovarian cancer does not have well-defined precursor lesions. It has more complex histological features and early stage cancer samples are more difficult to obtain. These differences limit our ability to identify risk factors, which are important for the pathogenesis of ovarian cancer. In the last decade, multiple endogenous and exogenous risk factors as well as genetic alterations have been identified for ovarian cancer. In this review, we will summarize some of these risk factors and genetic changes identified for all or specific histological types of ovarian can- 
cer, which may provide insights into the development of the disease.

\section{Histology}

Epithelial ovarian tumors are classified as benign, low malignant potential (borderline), or malignant according to the World Health Organization (WHO) criteria [3]. Benign epithelium is characterized by a single or minimally stratified layer of cells. These cells are columnar and often ciliated in serous tumors and contain abundant apical cytoplasmic mucin in mucinous tumors. Atypical epithelium lining of borderline or low malignant potential (LMP) tumor is characterized by cellular proliferation and pleomorphism without stromal invasion. Malignant epithelium demonstrates marked atypia, increased mitotic activity, and stromal invasion. Although the histopathologic features of ovarian tumors vary substantially, all tumors exhibit characteristics similar to those of the mullerian epithelium [4]. There are four major histological types of ovarian cancer. Serous tumors are the most common form of ovarian neoplasm with epithelial cells resembling those of the fallopian tube. They comprise about $50-60 \%$ of primary epithelial ovarian tumors. Mucinous tumors are cystic tumors with locules lined with mucin-secreting epithelial cells resembling either endocervical or colonic epithelium. They comprise approximately $8-10 \%$ of primary epithelial ovarian tumors. Endometrioid tumors are tumors with epithelial cells resembling endometrial glands of the endometrium and together with Clear cell lesions constitute about $10 \%$ of epithelial tumors. Other tumor cell types include Brenner, mixed epithelial type and undifferentiated.

\section{Epidemiology}

Although the etiology of ovarian cancer is unknown, scientists have proposed several hypotheses to explain the epidemiologic factors correlating with its incidence. Factors that have been associated with a lower risk of ovarian cancer include having had one or more fullterm pregnancies, having used oral contraceptives, having breast-fed, and having undergone a tubal ligation or hysterectomy [5]. All these events would tend to reduce the number of ovulations a woman has during her lifetime. And although early menarche - which may result in more ovulations - has not been associated with an increased incidence of ovarian cancer, studies have shown an increased incidence of ovarian cancer in women who are nulliparous, have had fewer pregnancies, have never breast-fed, or are infertileother conditions that may increase the number of ovulations in a woman's lifetime [4,6-8].

The apparent overall relationship between ovulations history and risk has prompted the development of several unified hypotheses of ovarian cancer pathogenesis.

\subsection{Hypothesis 1}

In the earliest of these, it was postulated that "incessant ovulation" leads to neoplastic transformation of HOSE cells $[9,10]$. This hypothesis states that every ovulation creates a wound that HOSE cells repair by undergoing postovulation mitosis and proliferation and that the increase in cell proliferation increases the likelihood that age- or toxin-caused aberrations in DNA repair mechanisms will permit genetic damage to go unrepaired and become potentially carcinogenic mutations [11-14]. Several studies have found evidence that supports the incessant ovulation hypothesis. In one, the repeated subculture of rat ovarian surface epithelium (OSE) cells induced spontaneous cellular transformation and chromosomal aberrations $[15,16]$. In another study, sheep OSE cells examined from the site of stigma formation showed evidence of oxidative DNA damage, p53 expression, and apoptosis [17].

\subsection{Hypothesis 2}

Another hypothesis explaining the relationship between ovulation history and ovarian cancer risk involves the exposure of HOSE cells to the ovarian stroma [18,19] (Fig. 1). Normally, the OSE is separated from the stroma by a basement membrane and a layer of thin connective tissue [11]. The formation of an inclusion cyst breaks down that barrier and brings HOSE cells into the hormonal milieu of the stroma, prompting neoplastic growth [20].

\subsection{Hypothesis 3}

The fact that the incidence of ovarian cancer increases dramatically in women above the age of 45 years and peaks between 10 and 20 years after menopause has led tothe development of a "gonadotropin stimulation" hypothesis, in which the elevated gonadotropin levels found in menopausal and postmenopausal women are a causative factor in ovarian cancer [20]. Support this hypothesis are results from several case stud- 


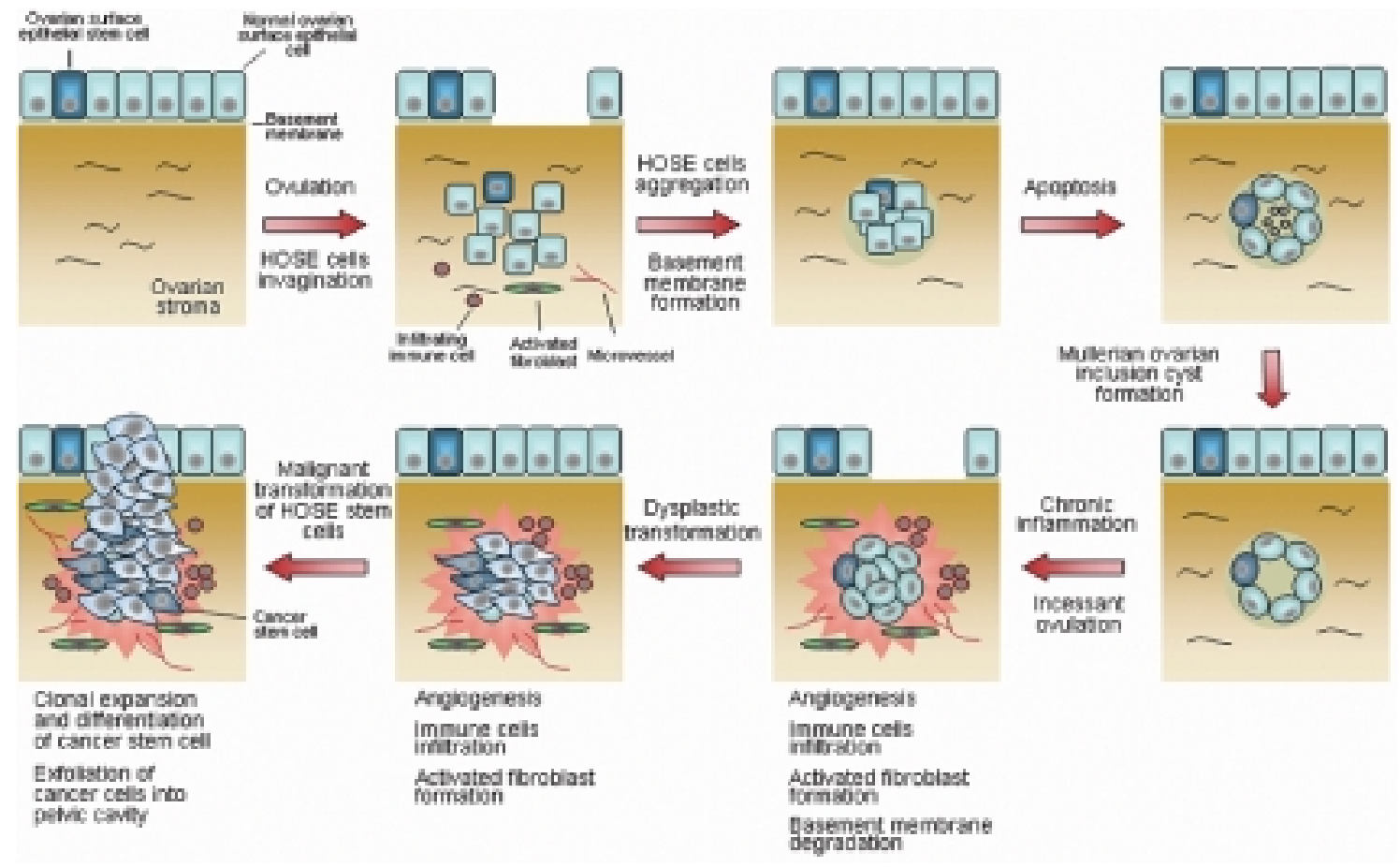

Fig. 1. Ovarian microenvironment and the initiation of an epithelial ovarian tumor. We hypothesize that microenvironment in the cortex of the ovary, which has been subjected to chronic inflammation due to either incessant ovulation and/or infection induces dysplatic changes in epithelial cells (including ovarian surface epithelial stem cells) lining the mullerian inclusion cyst. Immune cells infiltration, activated fibroblast formation, and microvessels proliferation combined with other factors in the microenvironment induce dysplastic and subsequently malignant transformation of the normal ovarian surface epithelia (HOSE) stem cell to a cancer stem cell, which gives rise to heterogenous daughter cells through clonal expansion and differentiation.

ies in which women developed ovarian cancer shortly after ovulation had been induced with clomiphene citrate, a gonadotropin formulation, or another fertility drug [21-23]. However, more recent studies have suggested that gonadotropins have a protective rather than inductive role in ovarian carcinogenesis. In one study, the serum levels of gonadotropins, particularly folliclestimulating hormone, were lower in ovarian cancer patients who were postmenopausal than in patients who were premenopausal [24]. In another study, a group of 25- to 49-year-old women with ovarian cancer had lower luteinizing hormone levels than their cancer-free peers [25].

\subsection{Hypothesis 4}

Like the gonadotropin stimulation hypothesis, epidemiologic observations made in the past decade suggest several other classes of hormones contribute to ovarian cancer pathogenesis, including androgens, estrogens, progesterone, and insulin-like growth factorI [26-28].
Most of these hypotheses have been focusing on the effect of risk factors on OES cells. However, there may be a specific group of cells that are more susceptible to malignant transformation. Based on recent cancer stem cell studies, it has been hypothesized that different histologic types of epithelial ovarian cancer are initiated by the malignant transformation of a corresponding progenitor or stem cell in the OSE. (Fig. 1) [29,30]. Uninterrupted cycles of ovulation and epithelial replenishment from mitotic stem cells increase the risk for development of ovarian cancer in nulliparous women [29, 30].

\section{Endogenous risk factors}

Combination of endogenous risk factors such as ovarian microenvironment and genetic polymorphisms may be acting on the epithelial progenitor cells in the OSE or mullerian epithelium of inclusion cysts, and those cells may have the potential to differentiate into different histologic types of ovarian tumors. In addi- 
tion, these factors may also act on other epithelial cell types, such as endometrial cells, which some studies have implicated as cells of origin in epithelial ovarian tumors [31].

\subsection{Inflammatory ovarian microenvironment}

Inflammation has been suggested to be a major factor leading to epithelial ovarian cancer. For example, epidemiologic data have shown that asbestos and talc exposure increased ovarian cancer risk [32]. Studies have also found that endometriosis [33], pelvic inflammatory disease [34], and mumps viral infection [35] are positively associate with ovarian cancer risk. In contrast, tubal ligations and hysterectomies, which are thought to reduce the exposure of the OSE to environmental inflammation initiators have been shown to reduce the risk of ovarian cancer [33,36,37]. It has been noted that the ovulatory process itself resembles an inflammatory reaction, with leukocytic infiltration, the release of nitric oxide and inflammatory cytokines, vasodilatation, DNA repair, and tissue remodeling [3842]. As epidemiological studies suggest that "incessant ovulation" may lead to neoplastic transformation of HOSE cells $[9,10]$ as described in previous section, the inflammatory responses the ovulation cycle causes may contribute to the development of ovarian cancer.

Several inflammatory factors, such as cytokines secreted by the infiltrating leukocytes have been implicated in ovarian carcinogenesis. Some studies suggest that pro-inflammatory cytokines play a major role in ovarian cancer pathogenesis because both ovarian tumors and normal tissue have been reported to have an abundance of these cytokines [43-45]. Tumor necrosis factor alpha (TNF- $\alpha$ ) is one of the key pro-inflammatory cytokines in ovarian function. One study showed that TNF- $\alpha$ was localized to the thecal endothelial cells of pre-ovulatory follicles, and its levels within the follicular apex declined abruptly as ovulation approached, whereas the level in cells within the counterpart basal wall was unaffected. TNF- $\alpha$ was secreted, within a limited diffusion radius, into the progenitor site of rupture [46]. Another study showed TNF- $\alpha$ was activated by plasmin in endothelial cells within the ovarycite 47 . It was suggested that the bioactive, soluble form of TNF- $\alpha$ generated from the endothelial cells of pre-ovulatory follicles may have an important role in the biomechanics of apical follicular weakening and ovarian rupture [46]. TNF- $\alpha$ was shown to contribute to basement membrane degradation during ovulation [48]. TNF- $\alpha$ was found to in- crease the activity of matrix metalloproteinase (MMP)9 and urokinase-type plasminogen activator secreted from HOSE cells, causing degradation and structural reorganization of the basement membrane components (collagen IV and laminin). This study implicates the potential roles of TNF-a, uPA, and MMP-9 in ovarian surface epithelial basement membrane degradation and remodeling, which are processes during ovulation and may contribute to epithelial transformation. It also may provide a molecular mechanism linking ovulation and ovarian cancer risk.

Besides the leukocytes, stromal fibroblasts in the inflammatory ovarian microenvironment may also support the development of tumors [49]. One of the molecules that is induced markedly by inflammation related growth factors and cytokines in the stromal fibroblast is tenascin- $\mathrm{C}$ [50-54]. Tenascin- $\mathrm{C}$ has been shown to be up-regulated in mammalian tissue of a MMP3 breast carcinogenesis model several weeks before signs of premalignant lesions were observed suggesting that tenascin-C plays an early role in tumorigenesis [55]. In addition, we have recently demonstrated that ovarian stromal fibroblast treated with TNF- $\alpha$ induced MMP-3 expression (personal communication). Since a recent study showed that mouse mammary epithelial cells exposed to MMP-3 induced the expression of an alternatively spliced form of Rac1, which caused an increase in cellular reactive oxygen species (ROS), and the ROS stimulated the expression of the transcription factor Snail and epithelial-mesenchymal transition (EMT), and caused oxidative damage to DNA and genomic instability [56], we hypothesize that upregulation of MMP-3 in an inflammatory stromal microenvironment may lead to malignant transformation of HOSE cells.

\subsection{Genetic factor}

In addition to risk factors that affect the ovarian microenvironment, other intrinsic factors, such as genetic polymorphisms, may play a role in the pathogenesis of different histologic types of ovarian cancer. For example, high-penetrance genes such as breast cancer 1, early onset (BRCAl) has been shown to increase the risk of epithelial ovarian cancer, particularly serous carcinoma [57]. Low-penetrance susceptibility genes have been shown to influence the risk of different histologic types of epithelial ovarian cancer. For example, the glutathione S-transferase M1 (GSTM1) null genotype has been associated with an increased risk of endometrioid or clear cell invasive cancer $[58,59]$. In addition, 
while possession of the A2 variant of P450c17alpha gene (CYP17) appeared to increase risk for all types of ovarian cancer, possession of the Val/Met variant of catechol-O-methyltransferase (COMT) decreased the risk for mucinous tumors [60]. These findings must be verified by independent studies with large case-control populations to further confirm the association between a particular polymorphism with ovarian cancer risk. In addition, further exploration of potential pathogenetic mechanisms is necessary. Using the newly developed high-throughput single nucleotide polymorphism genotyping platform [61] combined with a large population of case and control specimens, we should have the opportunity to identify genetic risk factors for the development of different histologic types of ovarian tumors.

\section{Pathogenetic pathways for different histologic types of ovarian cancer}

\subsection{Morphologic evidence}

While it is believed that the ovarian microenvironment plays a major role in the etiology of ovarian cancer, the pathogenetic pathways involved in the development of different histologic types of epithelial ovarian tumors remain largely unknown. The precursors of even the most common histologic types of epithelial ovarian cancer - serous and mucinous - have not yet been identified. However, several uncommon histopathologic features that have been identified in early-stage ovarian tumors may give insight into the pathogenesis of epithelial ovarian tumors (Fig. 2). First, both low- and high-grade mucinous ovarian carcinomas are frequently found to have coexisting benign, borderline, and invasive epithelial components [62,63]. In contrast, only a small percentage of low-grade or high-grade serous ovarian carcinomas contain all these types of components [63]. These data suggest that mucinous carcinomas but not serous carcinomas may develop from the benign or borderline lesions. Second, incidental microscopic serous carcinomas, which are high-grade carcinomas, have been identified in grossly normal ovaries [64]. This is further support the notion that high-grade serous carcinomas develop de novo and do not develop from benign or borderline lesions. Third, endosalpingiosis - which consists of one layer of well-demarcated columnar-to-cuboidal cells including ciliated cells - is frequently seen in the ovary and has been associated with serous cystadenocarcinoma suggesting that endosalpingiosis may represent the precursor for serous tumors [65-67].

\subsection{Molecular evidence}

Based on the above histopathologic findings and the prevalence of each histologic subtype of epithelial ovarian cancer, we developed a hypothesis to explain serous and mucinous ovarian tumor development (Fig. 2). This hypothesis states that most ovarian tumors develop from ovarian inclusion cysts arising from the OSE. In most cases of serous cancer, the majority of serous BOTs develop directly from ovarian inclusion cysts, without the cystadenoma stage. Alternatively, the epithelial lining of the cyst develops into a mucinous or serous cystadenoma by following one of two distinct pathogenetic pathways, as follows. A mucinous cystadenoma would give rise to a mucinous borderline ovarian tumor (BOT), a subset of which may progress, giving rise to invasive low- and perhaps highgrade grade mucinous carcinomas. A serous cystadenoma would give rise to a serous BOT, in which benign and borderline features are rare, in contrast to their frequent presence in mucinous BOTs. Our recent expression profiling analysis of serous BOTs and serous lowand high-grade carcinomas suggested that serous BOTs and low-grade carcinomas may represent developmental stages along a continuum of disease development and progression [68]. Thus, we hypothesize that a majority of high-grade serous carcinomas derive de novo from ovarian cysts or ovarian endosalpingiosis. This hypothesis is consistent with the two-tier system recently proposed for the grading serous carcinomas [69, 70]. Furthermore, we propose that serous carcinomas may also develop on the ovarian surface directly from OSE cells. This is supported by the finding that invasive serous carcinomas can be identified sitting on the surface of the ovary without any ovarian cortical stroma involvement.

Studying genetic changes in different types of ovarian tumors provide insight into the pathogenesis pathways for ovarian cancer. In a previous study, singlestrand conformation polymorphism analyses revealed Kirsten ras oncogene homolog (KRAS) mutations in BOTs, with mutations present in $63 \%$ of mucinous BOTs and $75 \%$ of invasive mucinous ovarian cancers [71]. These data suggest that KRAS mutations are involved in the development of mucinous BOTs and support the notion that mucinous BOTs may represent a phase of development along the pathologic continuum between benign and malignant mucinous tumors. Both serous BOTs and serous invasive ovarian cancers have demonstrated a lower KRAS mutation rate than mucinous tumors, but the KRAS mutation rate in serous 


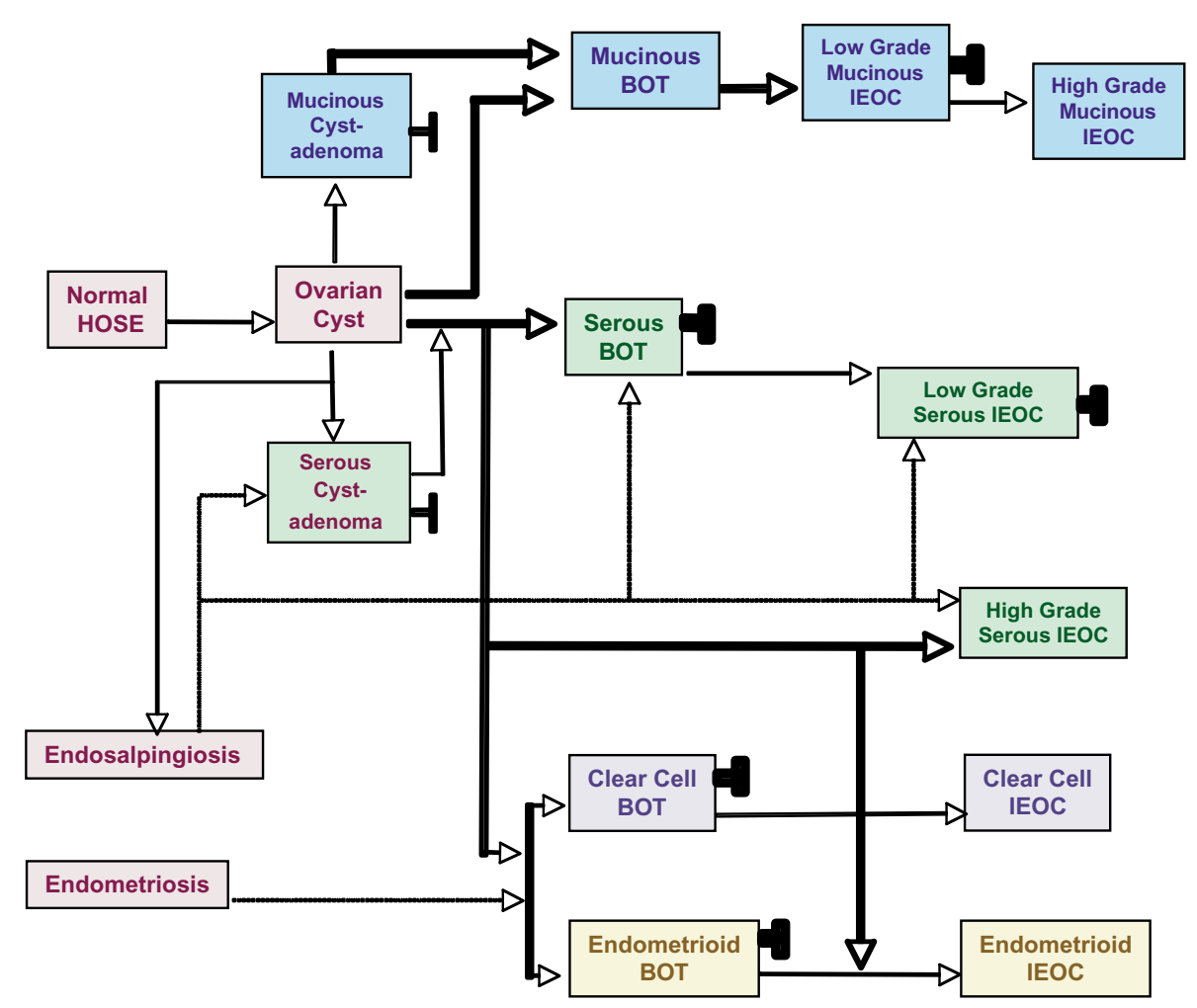

Fig. 2. Pathogenetic pathways of epithelial ovarian tumors of different histologic types. Most ovarian tumors develop from ovarian inclusion cysts arising from the OSE. In most cases of serous cancer, the majority of serous BOTs develop directly from ovarian inclusion cysts, without the cystadenoma stage. Alternatively, the epithelial lining of the cyst develops into a mucinous or serous cystadenoma by following one of two distinct pathogenetic pathways, as follows. A mucinous cystadenoma would give rise to a mucinous BOT, a subset of which may progress, giving rise to invasive low- and perhaps high-grade grade mucinous carcinomas. A serous cystadenoma or endosalpingiosis would give rise to a serous BOT, in which benign and borderline features are rare, in contrast to their frequent presence in mucinous BOTs. Serous BOTs and low-grade carcinomas may represent developmental stages along a continuum of disease development and progression. However, a majority of high-grade serous carcinomas derive de novo from ovarian cysts or ovarian endosalpingiosis. Endometrioid and clear cell carcinomas may develop from endometriosis. BOT, borderline ovarian tumor, IEOC, invasive epithelial ovarian cancer.

BOTs is significantly higher than that in serous invasive cancers. These data suggest that serous BOTs and invasive carcinomas may have different pathogenetic pathways, and only a small percentage of serous BOTs may progress to invasive cancers [71].

Loss of heterozygosity (LOH) studies have been widely used to identified minimally deleted regions where tumor suppressor genes may reside. We previously identified such several common loss regions by using 105 microsatellite markers to perform detailed deletion mapping on chromosomes 1, 3, 6, 7, 9, 11, 17, and $\mathrm{X}$ in BOTs, invasive ovarian cancers, and serous surface carcinoma of the ovary. Except at the androgen receptor (AR) locus on the X chromosome [72], BOTs showed significantly lower $\mathrm{LOH}$ rates $(0 \%-18 \%)$ than invasive tumors at all loci screened, suggesting that the $\mathrm{LOH}$ rate at autosomes is less important in the development of BOTs than more advanced tumors. Based on these and other results, the importance of $\mathrm{LOH}$ at the AR locus in BOTs and invasive cancers remains undetermined. However, several studies have found differences in $\mathrm{LOH}$ rates on other chromosomes. $\mathrm{LOH}$ at the p73 locus on 1p36 was found in both high- and low-grade ovarian and surface serous carcinomas, but not in borderline ovarian tumors. In one study, $\mathrm{LOH}$ rates at 3p25, 6q25.1-26, and 7q31.3 were significantly higher in high-grade serous carcinomas than in lowgrade serous carcinomas, mucinous carcinomas, and borderline tumors [73-75]. In another study, LOH rate at a 9-cM region on 6q23-24 were significantly higher in surface serous carcinomas than in serous ovarian tumors [76]. In addition, multiple minimally deleted regions have been identified on chromosomes 11 and 17. LOH at a 4-cM region on chromosome 11p15.1 and an 11-cM region on chromosome $11 \mathrm{p} 15.5$ were found only in serous invasive tumors, and the $\mathrm{LOH}$ rates in 
$11 \mathrm{p} 15.1$ and $11 \mathrm{p} 15.5$ were significantly higher in highgrade than low-grade serous tumors [77]. Similarly, significantly higher $\mathrm{LOH}$ rates were identified at the TP53 locus on 17p13.1 and the NF1 locus on 17q11.1 in high-grade serous carcinomas than in low-grade and borderline serous tumors and all mucinous tumors [78]. LOH at the region between THRA1 and D17S1327, including the BRCA1 locus on 17q21, was found exclusively in high-grade serous tumors [79]. In general, the fact that $\mathrm{LOH}$ rates at multiple chromosomal sites were significantly higher in serous than in mucinous tumor subtypes suggest that serous and mucinous tumors may have different pathogenetic pathways. Since tumor suppressor genes are implicated to be located in chromosomal regions demonstrating with $\mathrm{LOH}$, further analysis in genes located in the minimal deleted regions may provide insights into genes that may be important for the pathogenesis of serous and mucinous ovarian tumors.

Studying genetic changes in endometriosis, endometrioid and clear cell ovarian cancer also provides insights into pathogeneitc pathways in the development of these tumor types. Endometriosis is highly associated with endometrioid and clear cell carcinomas $(28 \%$ and $49 \%$, respectively), in contrast to its very low frequency of association with serous and mucinous carcinomas of the ovary (3\% and $4 \%$, respectively) [80]. This fact furnishes strong evidence that endometriosis is a precancerous lesion for both endometrioid and clear cell carcinomas. Using a molecular genetic approach, Campbell et al. [81] and Jiang et al. [82] detected genetic lesions common to the carcinoma and the adjacent endometriotic tissue; Obata et al. [83] showed that endometrioid but not serous or mucinous epithelial ovarian tumors had frequent PTEN/MMAC mutations. In addition, the loss of PTEN immunoreactivity has been reported in a significantly higher percentage of clear cell and endometrioid ovarian cancers than cancers of other histologic types [84]. Dinulescu et al. [85] recently demonstrated that the expression of oncogenic KRAS or conditional PTEN deletion within the OSE induces preneoplastic ovarian lesions with an endometrioid glandular morphology. Furthermore, the combination of the two mutations in the ovary led to the induction of invasive and widely metastatic endometrioid ovarian adenocarcinomas. These data further suggest that tumors with different histologic subtypes may arise through distinct developmental pathways.

\section{Conclusions and future directions}

The pathogenesis of ovarian cancer is a complex process, which may involve the interaction of HOSE, progenitor stem cells or ovarian endometriotic cells with the stromal cells in an inflammatory ovarian microenvironment. That in turn may induce the dysplastic and subsequently malignant transformation and differentiation of these cells into different histologic types of ovarian cancer. Interactions between environmental and other intrinsic risk factors, such as genetic polymorphisms, certainly play a role in the pathogenesis of different histologic types of ovarian cancer. The development of microdissection and cell separation technologies enables investigators to dissect out each component of the normal and tumor tissue and examine gene expression profiles of each component. The application of newly developed three dimension (3D) culture and animal models, and SNP analysis on a large collection of case and control samples will certainly help us to delineate the underlying molecular mechanisms in the development of different histological types of ovarian cancer.

\section{Acknowledgements}

This study was supported in part by R33CA103595 and the Ovarian Cancer SPORE CA105009 from The National Institute of Health, Department of Health and Human Services; The Gillette Center For Women's Cancer, Adler Foundation, Inc., Edgar Astrove Fund, The Ovarian Cancer Research Fund, Inc., The Morse Family Fund, and The Natalie Pihl Fund, and the Ruth N. White Research Fellowship.

\section{References}

[1] American Cancer Society, I. American Cancer Society, Cancer Facts and Figures-2005. www.cancer.org/docroot/ STT/stt_0.asp, 2005.

[2] D.A. Bell and R.E. Scully, Clinical perspective on borderline tumors of the ovary, Current Topics in Obstetrics and Gynecology, Elsevier Science Publishing Co., Inc, 1991, 119-133.

[3] S.F. Serov and R.E. Scullt, Histological typing of ovarian tumors (International Histological Classification of Tumors No. 9), Geneva: World Health Organization, 1993.

[4] B.R. Rao and B.J. Slotman, Endocrine factors in common epithelial ovarian cancer, Endocr Rev 12 (1991), 14-26.

[5] G. Tortolero-Luna and M.F. Mitchell, The epidemiology of ovarian cancer, J Cell Biochem Suppl 23 (1995), 200-207.

[6] D.W. Cramer, W.R. Welch, R.E. Scully and C.A. Wojciechowski, Ovarian cancer and talc: a case-control study, Cancer 50 (1982), 372-376. 
[7] G. Kvale, I. Heuch, S. Nilssen and V. Beral, Reproductive factors and risk of ovarian cancer: a prospective study, Int $J$ Cancer 42 (1988), 246-251.

[8] A.S. Whittemore, R. Harris and J. Itnyre, Characteristics relating to ovarian cancer risk: collaborative analysis of 12 US case-control studies. II. Invasive epithelial ovarian cancers in white women. Collaborative Ovarian Cancer Group, Am J Epidemiol 136 (1992), 1184-1203.

[9] M.F. Fathalla, Incessant ovulation-a factor in ovarian neoplasia? Lancet 2 (1971), 163.

[10] J.T. Casagrande, E.W. Louie, M.C. Pike, S. Roy, R.K. Ross and B.E. Henderson, Incessant ovulation and ovarian cancer, Lancet 2 (1979), 170-173.

[11] N. Auersperg, I.A. Maclaren and P.A. Kruk, Ovarian surface epithelium: autonomous production of connective tissue-type extracellular matrix, Biol Reprod 44 (1991), 717-724.

[12] P.A. Cerutti, Prooxidant states and tumor promotion, Science 227 (1985), 375-381.

[13] B.N. Ames and L.S. Gold, Carcinogenesis debate, Science 250 (1990), 1498-1499.

[14] S.M. Cohen and L.B. Ellwein, Cell proliferation in carcinogenesis, Science 249 (1990), 1007-1011.

[15] A.K. Godwin, J.R. Testa, L.M. Handel, Z. Liu, L.A. Vanderveer, P.A. Tracey and T.C. Hamilton, Spontaneous transformation of rat ovarian surface epithelial cells: association with cytogenetic changes and implications of repeated ovulation in the etiology of ovarian cancer, J Natl Cancer Inst 84 (1992), 592-601.

[16] J.R. Testa, L.A. Getts, H. Salazar, Z. Liu, L.M. Handel, A.K. Godwin and T.C. Hamilton, Spontaneous transformation of rat ovarian surface epithelial cells results in well to poorly differentiated tumors with a parallel range of cytogenetic complexity, Cancer Res 54 (1994), 2778-2784.

[17] W.J. Murdoch, R.S. Townsend and A.C. McDonnel, Ovulation-induced DNA damage in ovarian surface epithelial cells of ewes: prospective regulatory mechanisms of repair/survival and apoptosis, Biol Reprod 65 (2001), 14171424.

[18] E.C. Brooks, N.N. Mahr, Z. Radisavljevic, E.D. Jacobson and L.S. Terada, Nitric oxide attenuates and xanthine oxidase exaggerates lung damage-induced gut injury, Am J Physiol 272 (1997), G845-852.

[19] A. Blaustein, Surface cells and inclusion cysts in fetal ovaries, Gynecol Oncol 12 (1981), 222-233.

[20] D.W. Cramer and W.R. Welch, Determinants of ovarian cancer risk. II. Inferences regarding pathogenesis, J Natl Cancer Inst 71 (1983), 717-721.

[21] R. Kulkarni and J.M. McGarry, Follicular stimulation and ovarian cancer, BMJ 299 (1989), 740.

[22] G.L. Goldberg and C.D. Runowicz, Ovarian carcinoma of low malignant potential, infertility, and induction of ovulation-is there a link? Am J Obstet Gynecol 166 (1992), 853-854.

[23] M.A. Rossing, J.R. Daling, N.S. Weiss, D.E. Moore and S.G. Self, Ovarian tumors in a cohort of infertile women, $N$ Engl $J$ Med 331 (1994), 771-776.

[24] J. Blaakaer, H. Djursing, U. Hording, P. Bennett, K. ToftagerLarsen, J.E. Bock and P.E. Lebech, The pituitary-gonadal axis in women with benign or malignant ovarian tumors, Acta Endocrinol (Copenh) 127 (1992), 127-130.

[25] D.W. Cramer, R.L. Barbieri, H. Xu and J.K. Reichardt, Determinants of basal follicle-stimulating hormone levels in premenopausal women, J Clin Endocrinol Metab 79 (1994), 1105-1109.
[26] H.A. Risch, Hormonal etiology of epithelial ovarian cancer, with a hypothesis concerning the role of androgens and progesterone, J Natl Cancer Inst 90 (1998), 1774-1786.

[27] S.M. Ho, K.M. Lau, S.C. Mok and V. Syed, Profiling follicle stimulating hormone-induced gene expression changes in normal and malignant human ovarian surface epithelial cells, Oncogene 22 (2003), 4243-4256.

[28] A. Lukanova and R. Kaaks, Endogenous hormones and ovarian cancer: epidemiology and current hypotheses, Cancer Epidemiol Biomarkers Prev 14 (2005), 98-107.

[29] W.J. Murdoch and A.C. McDonnel, Roles of the ovarian surface epithelium in ovulation and carcinogenesis, Reproduction 123 (2002), 743-750.

[30] C.E. Gargett, Stem cells in gynaecology, Aust N Z J Obstet Gynaecol 44 (2004), 380-386.

[31] L. Dubeau, The cell of origin of ovarian epithelial tumors and the ovarian surface epithelium dogma: does the emperor have no clothes? Gynecol Oncol 72 (1999), 437-442.

[32] D.W. Cramer, R.F. Liberman, L. Titus-Ernstoff, W.R. Welch, E.R. Greenberg, J.A. Baron and B.L. Harlow, Genital talc exposure and risk of ovarian cancer, Int J Cancer 81 (1999), 351-356.

[33] A. Melin, P. Sparen, I. Persson and A. Bergqvist, Endometriosis and the risk of cancer with special emphasis on ovarian cancer, Hum Reprod 21 (2006), 1237-1242.

[34] F. Parazzini, C. La Vecchia, E. Negri, S. Moroni, D. dal Pino and L. Fedele, Pelvic inflammatory disease and risk of ovarian cancer, Cancer Epidemiol Biomarkers Prev 5 (1996), 667669.

[35] K.A. Rosenblatt and N.B. Rosenshein, Mumps parotitis and ovarian cancer, Am J Obstet Gynecol 149 (1984), 472-474.

[36] R.B. Ness and C. Cottreau, Possible role of ovarian epithelial inflammation in ovarian cancer, J Natl Cancer Inst 91 (1999), 1459-1467.

[37] R.B. Ness, J.A. Grisso, C. Cottreau, J. Klapper, R. Vergona, J.E. Wheeler, M. Morgan and J.J. Schlesselman, Factors related to inflammation of the ovarian epithelium and risk of ovarian cancer, Epidemiology 11 (2000), 111-117.

[38] L.L. Espey, Current status of the hypothesis that mammalian ovulation is comparable to an inflammatory reaction, Biol Reprod 50 (1994), 233-238.

[39] L.L. Espey, Ovulation as an inflammatory reaction-a hypothesis, Biol Reprod 22 (1980), 73-106.

40] N. Bonello, K. McKie, M. Jasper, L. Andrew, N. Ross, E. Braybon, M. Brannstrom and R.J. Norman, Inhibition of nitric oxide: effects on interleukin-1 beta-enhanced ovulation rate, steroid hormones, and ovarian leukocyte distribution at ovulation in the rat, Biol Reprod 54 (1996), 436-445.

[41] J.S. Richards, D.L. Russell, S. Ochsner and L.L. Espey, Ovulation: new dimensions and new regulators of the inflammatorylike response, Annu Rev Physiol 64 (2002), 69-92.

[42] J.S. Fleming, C.R. Beaugie, I. Haviv, G. Chenevix-Trench and O.L. Tan, Incessant ovulation, inflammation and epithelial ovarian carcinogenesis: revisiting old hypotheses, Mol Cell Endocrinol 247 (2006), 4-21.

[43] J.M. Burke, D.J. Carroll, K.E. Rowe, W.W. Thatcher and F. Stormshak, Intravascular infusion of lipid into ewes stimulates production of progesterone and prostaglandin, Biol Reprod $\mathbf{5 5}$ (1996), 169-175.

[44] M.A. Nash, G. Ferrandina, M. Gordinier, A. Loercher and R.S. Freedman, The role of cytokines in both the normal and malignant ovary, Endocr Relat Cancer 6 (1999), 93-107. 
[45] J. Wilson and F. Balkwill, The role of cytokines in the epithelial cancer microenvironment, Semin Cancer Biol 12 (2002), 113120.

[46] W.J. Murdoch, D.C. Colgin and J.A. Ellis, Role of tumor necrosis factor-alpha in the ovulatory mechanism of ewes, $J$ Anim Sci 75 (1997), 1601-1605.

[47] W.J. Murdoch, E.A. Van Kirk and J. Murdoch, Plasmin cleaves tumor necrosis factor alpha exodomain from sheep follicular endothelium: implication in the ovulatory process, Biol Reprod 60 (1999), 1166-1171.

[48] W.L. Yang, A.K. Godwin and X.X. Xu, Tumor necrosis factoralpha-induced matrix proteolytic enzyme production and basement membrane remodeling by human ovarian surface epithelial cells: molecular basis linking ovulation and cancer risk, Cancer Res 64 (2004), 1534-1540.

[49] D. Medina, Stromal fibroblasts influence human mammary epithelial cell morphogenesis, Proc Natl Acad Sci USA 101 (2004), 4723-4724.

[50] M. Jinnin, H. Ihn, Y. Asano, K. Yamane, M. Trojanowska and K. Tamaki, Tenascin-C upregulation by transforming growth factor-beta in human dermal fibroblasts involves Smad3, Sp1, and Ets1, Oncogene 23 (2004), 1656-1667.

[51] H.A. Makhluf, J. Stepniakowska, S. Hoffman, E. Smith, E.C. LeRoy and M. Trojanowska, IL-4 upregulates tenascin synthesis in scleroderma and healthy skin fibroblasts, $J$ Invest Dermatol 107 (1996), 856-859.

[52] W.J. Rettig, H.P. Erickson, A.P. Albino and P. Garin-Chesa, Induction of human tenascin (neuronectin) by growth factors and cytokines: cell type-specific signals and signalling pathways, J Cell Sci 107(Pt 2) (1994), 487-497.

[53] Y. Nakamura, S. Esnault, T. Maeda, E.A. Kelly, J.S. Malter and N.N. Jarjour, Ets-1 regulates TNF-alpha-induced matrix metalloproteinase-9 and tenascin expression in primary bronchial fibroblasts, J Immunol 172 (2004), 1945-1952.

[54] S.S. McCachren and V. Lightner, A. Expression of human tenascin in synovitis and its regulation by interleukin-1, Arthritis Rheum 35 (1992), 1185-1196.

[55] N. Thomasset, A. Lochter, C.J. Sympson, L.R. Lund, D.R. Williams, O. Behrendtsen, Z. Werb and M.J. Bissell, Expression of autoactivated stromelysin-1 in mammary glands of transgenic mice leads to a reactive stroma during early development, Am J Pathol 153 (1998), 457-467.

[56] D.C. Radisky, D.D. Levy, L.E. Littlepage, H. Liu, C.M. Nelson, J.E. Fata, D. Leake, E.L. Godden, D.G. Albertson, M.A. Nieto, Z. Werb and M.J. Bissell, Rac1b and reactive oxygen species mediate MMP-3-induced EMT and genomic instability, Nature 436 (2005), 123-127.

[57] M. Arai, J. Utsunomiya and Y. Miki, Familial breast and ovarian cancers, Int J Clin Oncol 9 (2004), 270-282.

[58] A.B. Spurdle, J.L. Hopper, X. Chen, G.S. Dite, M.R. McCredie, G.G. Giles, D.J. Venter, M.C. Southey, D.M. Purdie and G. Chenevix-Trench, The steroid 5alpha-reductase type II TA repeat polymorphism is not associated with risk of breast or ovarian cancer in Australian women, Cancer Epidemiol Biomarkers Prev 10 (2001), 1287-1293.

[59] S.W. Baxter, D.Y. Choong, D.M. Eccles and I.G. Campbell, Polymorphic variation in CYP19 and the risk of breast cancer, Carcinogenesis 22 (2001), 347-349.

[60] E.I. Garner, E.E. Stokes, R.S. Berkowitz, S.C. Mok and D.W. Cramer, Polymorphisms of the estrogen-metabolizing genes CYP17 and catechol-O-methyltransferase and risk of epithelial ovarian cancer, Cancer Res 62 (2002), 3058-3062.

[61] X. Zhou, S.C. Mok, Z. Chen, Y. Li and D.T. Wong, Concurrent analysis of loss of heterozygosity (LOH) and copy number ab- normality (CNA) for oral premalignancy progression using the Affymetrix 10K SNP mapping array, Hum Genet 115 (2004), 327-330.

[62] L.E. Puls, D.E. Powell, P.D. DePriest, H.H. Gallion, J.E. Hunter, R.J. Kryscio and J.R. van Nagell, Transition from benign to malignant epithelium in mucinous and serous ovarian cystadenocarcinoma, Gynecol Oncol 47 (1992), 53-57.

[63] R.E. Scully, D.A. Bell and G.M. Abu-Jawdeh, Update on early ovarian cancer and cancer developing in benign ovarian tumors, in: Ovarian Cancer 3, F. Sharp, P. Mason, T. Blackett and J. Berek, eds, London: Chapman \& Hall Medical, 1992, pp. 139-144.

[64] D.A. Bell and R.E. Scully, Early de novo ovarian carcinoma. A study of fourteen cases, Cancer 73 (1994), 1859-1864.

[65] B.G. Tutschka and S.C. Lauchlan, Endosalpingiosis, Obstet Gynecol 55 (1980), 57S-60S.

[66] R.E. Burmeister, R.E. Fechner and R.R. Franklin, Endosalpingiosis of the peritoneum, Obstet Gynecol 34 (1969), 310-318.

[67] R. Schuldenfrei and N.A. Janovski, Disseminated endosalpingiosis associated with bilateral papillary serous cystadenocarcinoma of the ovaries, Am J Obstet Gynecol 84 (1962), 382.

[68] T. Bonome, J.Y. Lee, D.C. Park, M. Radonovich, C. PiseMasison, J. Brady, G.J. Gardner, K. Hao, W.H. Wong, J.C. Barrett, K.H. Lu, A.K. Sood, D.M. Gershenson, S.C. Mok and M.J. Birrer, Expression profiling of serous low malignant potential, low-grade, and high-grade tumors of the ovary, Cancer Res 65 (2005), 10602-10612.

[69] M. Shih Ie and R.J. Kurman, Ovarian tumorigenesis: a proposed model based on morphological and molecular genetic analysis, Am J Pathol 164 (2004), 1511-1518.

[70] A. Malpica, M.T. Deavers, K. Lu, D.C. Bodurka, E.N. Atkinson, D.M. Gershenson and E.G. Silva, Grading ovarian serous carcinoma using a two-tier system, Am J Surg Pathol 28 (2004), 496-504.

[71] S.C. Mok, D.A. Bell, R.C. Knapp, P.M. Fishbaugh, W.R. Welch, M.G. Muto, R.S. Berkowitz and S.W. Tsao, Mutation of K-ras protooncogene in human ovarian epithelial tumors of borderline malignancy, Cancer Res 53 (1993), 1489-1492.

[72] M.I. Edelson, C.C. Lau, C.V. Colitti, W.R. Welch, D.A. Bell, R.S. Berkowitz and S.C. Mok, A one centimorgan deletion unit on chromosome $\mathrm{Xq} 12$ is commonly lost in borderline and invasive epithelial ovarian tumors, Oncogene 16 (1998), 197-202.

[73] J. Tangir, N.S. Loughridge, R.S. Berkowitz, M.G. Muto, D.A. Bell, W.R. Welch and S.C. Mok, Frequent microsatellite instability in epithelial borderline ovarian tumors, Cancer Res 56 (1996), 2501-2505.

[74] C.V. Colitti, K.J. Rodabaugh, W.R. Welch, R.S. Berkowitz and S.C. Mok, A novel $4 \mathrm{cM}$ minimal deletion unit on chromosome 6q25.1-q25.2 associated with high grade invasive epithelial ovarian carcinomas, Oncogene 16 (1998), 555-559.

[75] M.I. Edelson, S.W. Scherer, L.C. Tsui, W.R. Welch, D.A. Bell, R.S. Berkowitz and S.C. Mok, Identification of a 1300 kilobase deletion unit on chromosome 7q31.3 in invasive epithelial ovarian carcinomas, Oncogene 14 (1997), 2979-2984.

[76] L.W. Huang, A.P. Garrett, J.O. Schorge, M.G. Muto, D.A. Bell, W.R. Welch, R.S. Berkowitz and S.C. Mok, Distinct allelic loss patterns in papillary serous carcinoma of the peritoneum, Am J Clin Pathol 114 (2000), 93-99.

[77] K.H. Lu, J.N. Weitzel, S. Kodali, W.R. Welch, R.S. Berkowitz and S.C. Mok, A novel 4-cM minimally deleted region on chromosome 11p15.1 associated with high grade nonmuci- 
nous epithelial ovarian carcinomas, Cancer Res 57 (1997), $387-390$.

[78] I. Wertheim, J. Tangir, M.G. Muto, W.R. Welch, R.S Berkowitz, W.Y. Chen and S.C. Mok, Loss of heterozygosity of chromosome 17 in human borderline and invasive epithelial ovarian tumors, Oncogene 12 (1996), 2147-2153.

[79] J. Tangir, M.G. Muto, R.S. Berkowitz, W.R. Welch, D.A. Bell and S.C. Mok, A $400 \mathrm{~kb}$ novel deletion unit centromeric to the BRCA1 gene in sporadic epithelial ovarian cancer, Oncogene 12 (1996), 735-740.

[80] P. Russell, The pathological assessment of ovarian neoplasms. I: Introduction to the common 'epithelial' tumours and analysis of benign 'epithelial' tumours, Pathology 11 (1979), 5-26.

[81] I.G. Campbell, S. Morland and A. Hitchcock, Endometriosis and the relationship with ovarian cancer, in: Ovarian Cancer 5, F. Sharp, T. Blackett, J. Derek and R. Bast, eds, Oxford: ISIS Medical Media Ltd., 1998, pp. 159-170.
[82] X. Jiang, S.J. Morland, A. Hitchcock, E.J. Thomas and I.G. Campbell, Allelotyping of endometriosis with adjacent ovarian carcinoma reveals evidence of a common lineage, Cancer Res 58 (1998), 1707-1712.

[83] K. Obata, S.J. Morland, R.H. Watson, A. Hitchcock, G. Chenevix-Trench, E.J. Thomas and I.G. Campbell, Frequent PTEN/MMAC mutations in endometrioid but not serous or mucinous epithelial ovarian tumors, Cancer Res 58 (1998), 2095-2097.

[84] Y. Hashiguchi, H. Tsuda, T. Inoue, R.S. Berkowitz and S.C. Mok, PTEN expression in clear cell adenocarcinoma of the ovary, Gynecol Oncol 101 (2006), 71-75.

[85] D.M. Dinulescu, T.A. Ince, B.J. Quade, S.A. Shafer, D. Crowley and T. Jacks, Role of K-ras and Pten in the development of mouse models of endometriosis and endometrioid ovarian cancer, Nat Med 11 (2005), 63-70. 


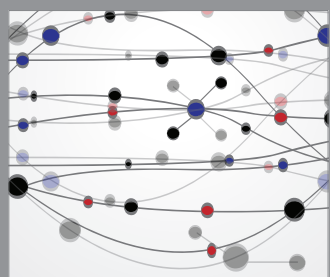

The Scientific World Journal
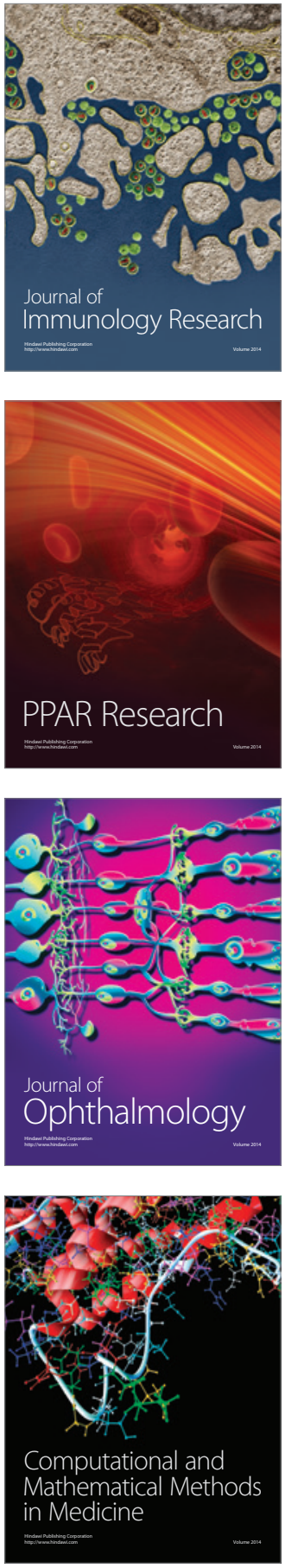

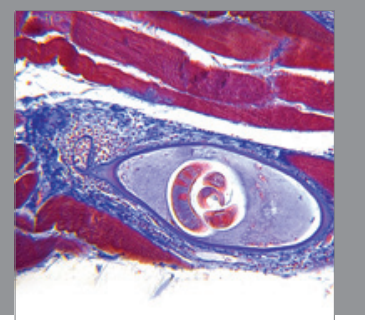

Gastroenterology

Research and Practice
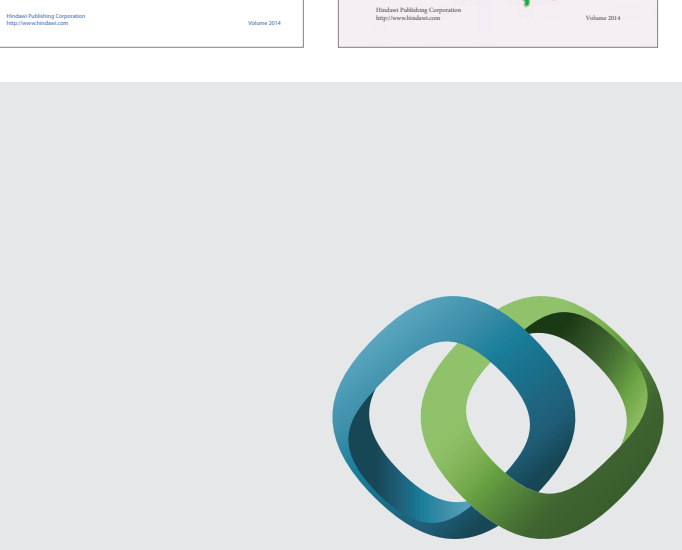

\section{Hindawi}

Submit your manuscripts at

http://www.hindawi.com
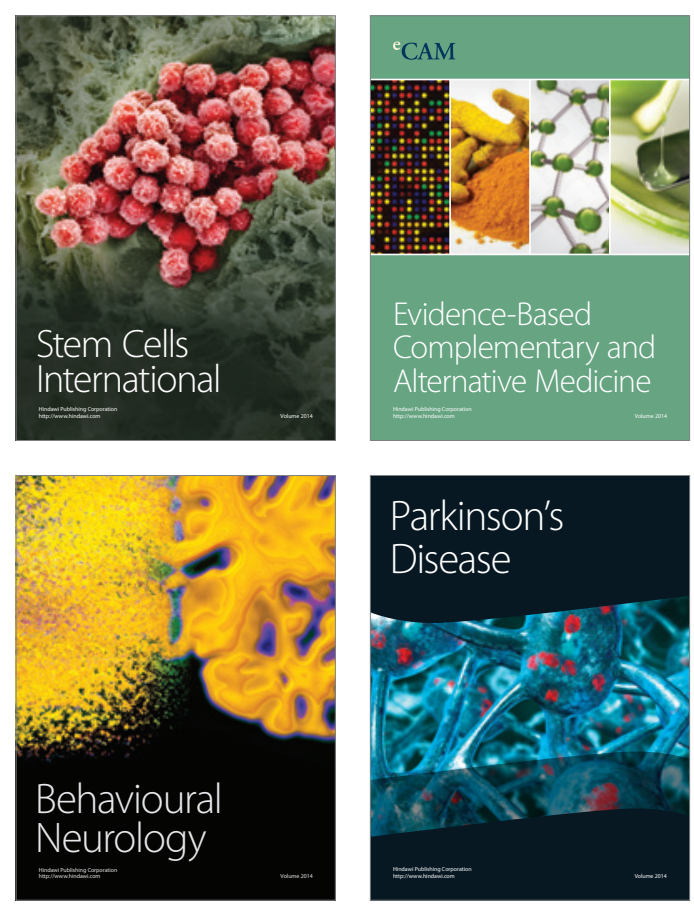

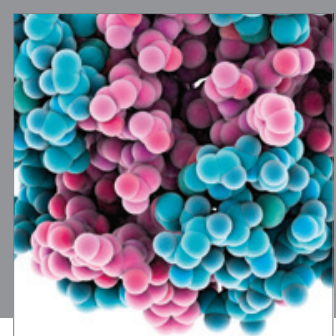

Journal of
Diabetes Research

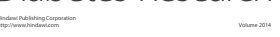

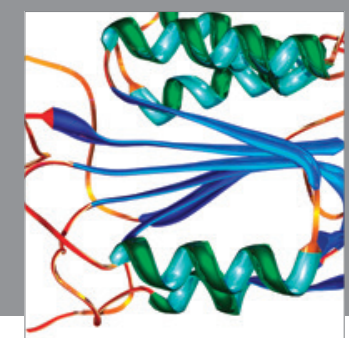

Disease Markers
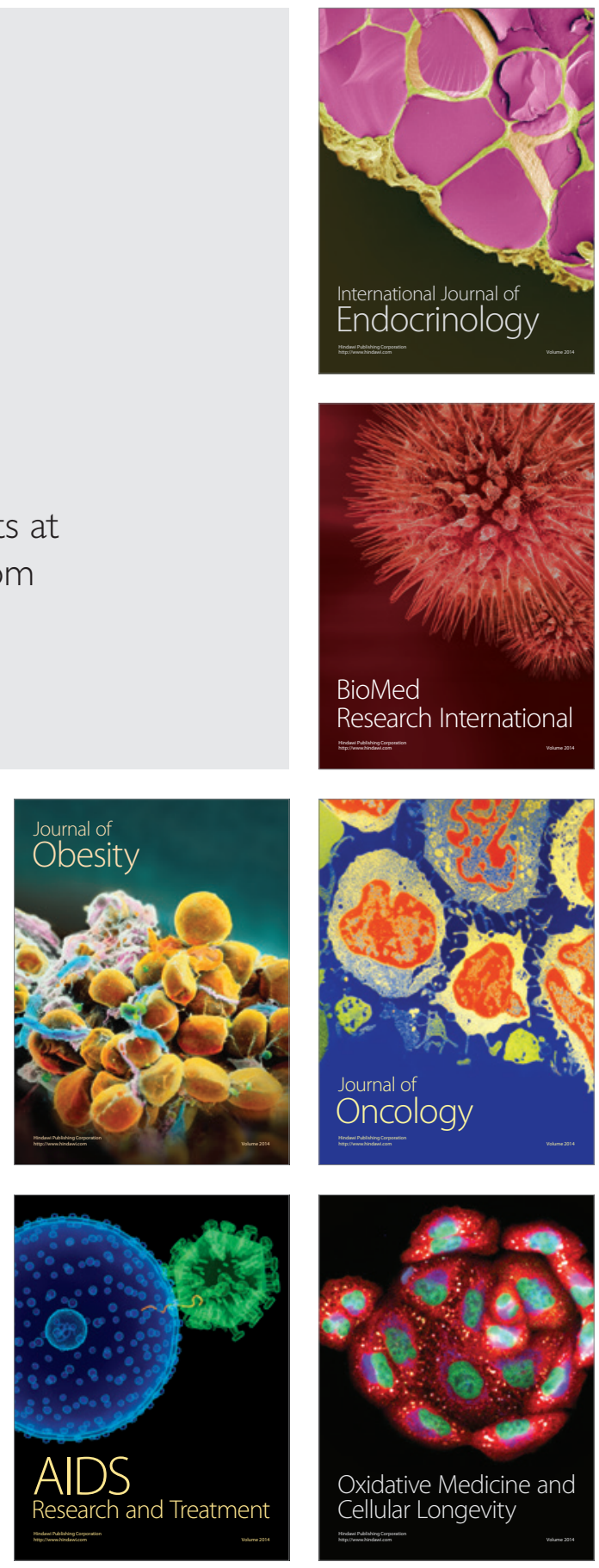